\title{
Online Learner Satisfaction: Learner-Instructor Discourse
}

Peter Kiriakidis, (Email: panto@primus.ca), Walden University, Canada

\begin{abstract}
This paper discusses the importance of the direct relationship between instructor discourse and learner discourse in the online learning environment during mandatory online discussions. It provides meaningful insights toward pedagogical theory and corresponding instructional practices associated with these two factors: (a) the extent of instructor discourse and (b) the extent of learner discourse within the online learning environment.
\end{abstract}

\section{INTRODUCTION}

his research study used the path analysis model (Figure 1) to examine the hypothesized direct
relationship between the extent of instructor asynchronous discourse and the extent of student
asynchronous discourse.

Figure 1

The Direct Hypothesized Relationship - Path Analysis Model

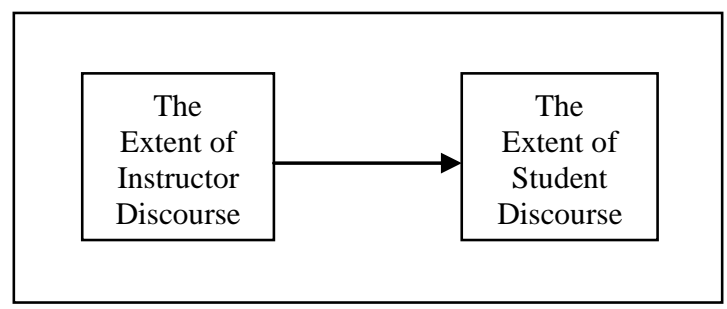

\section{THE RESEARCH PROBLEM}

The institution of higher education is becoming an increasingly competitive marketplace where budget cuts and funding limitations are forcing nearly all colleges and universities to compete for student enrollments (Arbaugh, 2000; Bullen, 1998; Taylor, 2002; Whitney, 2001). Among one of the growing competitors in this market place is the online university.

With minimal, if any, limitations imposed by time and place, the online university is gaining considerable popularity among those seeking a higher education (Bullen, 1998; Cannon, 2001; Deal, 2002; Furst-Bowe, 1997; Kearsley, 2002; King \& Hildreth, 2001; Picciano, 2001; Schott Karr, 2002). Within this competitive marketplace of higher education, the extent of both instructor and student discourse that may foster student satisfaction is clearly a factor of great importance (Arbaugh, 2000; Devi, 2001; Gunawardena \& Zittle, 1997; Mayzer \& Dejong, 2003). 


\section{STUDENT SATISFACTION}

In the online learning environment, feelings of isolation, due to the lack of face-to-face interactivity between students and instructors, and among students, have been well cited as a detrimental factor impacting levels of student satisfaction (Pennington and Wilkinson and Vance, 2004; Bullen, 1998; Berman and Tinker, 1997; Daly and Kreiser, 1992; Bernard and Amundsen, 1989). To overcome feelings of isolation, the importance of establishing a sense of community among groups of students within the online learning environment has become well recognized (Rovai, 2002; Dede, 1996).

Community is what gives students a sense of belonging and connectedness to their schools (Havice and Chang, 2002). Crawford (2001) asserts that students must have the ability to collaborate with other students and build a sense of community in order to retain a motivational level necessary to successfully complete an online course. Existing research has shown that asynchronous text-based discourse to be an important element fostering sense of community (Gunawardena and Zittle, 1997; Whitney Gibson, Tesone, and Blackwell, 2001). Intertwined throughout the research on student satisfaction and fostering communities in the online learning environment is the role of the instructor.

\section{THE ROLE OF THE INSTRUCTOR}

Existing research has emphasized that teaching online calls for instructors to take on an intellectual, as well as a social role - building relationships and fostering a sense of community among groups of students in the online learning environment (Palloff and Pratt, 1999; Arbaugh, 2000; McFadzean, 2001; Overbaugh, 2002). A high degree of interactivity and participation is the most important role of the instructor in online classes (Kearsley, 2000). The role of the instructor is transformed into the role of a facilitator (Kochtanek, 2000; Youngblood and Trede and De Corpo, 2001) who guides and supports students in creating learning communities through interactions in studentstudent(s) and instructor-student(s) communications.

\section{CONCEPTUAL FRAMEWORK}

Intricately connected with the direct relationship between the extent of instructor asynchronous discourse and the extent of student asynchronous discourse is the role of the instructor as a facilitator of meaningful discourse, community building, and student satisfaction in the online learning environment (Shea, Pickett, and Pelz, 2003; Furst-Bowe, 1997; Barker, 1995). This study was interested in student and instructor interactive discourse via asynchronous discussion forums. Asynchronous discussion forums are considered a communication tool used for interactivity purposes and are described in terms of instructor and student asynchronous discourse in the online learning environment.

The online learning environment is a concept broadly used to refer to learning opportunities offered via the Internet (Deal, 2002; Furst-Bowe, 1997; Hedges \& Mania-Farnell; 1999). The Internet provides digital communication enabling students to have access to: (a) online academic courses; (b) academic resources; (c) instructors referred to as mentors or facilitators; and (c) methods of communication including asynchronous discussions.

Within the context of the online learning environment, an array of technologies is used to deliver instruction and facilitate learning. Included among these technologies are asynchronous and/or synchronous video, audio, and text-based instructional tools and learning mediums. Among this array of technologies, the usage of asynchronous text is a common component found within many online learning environments. During asynchronous discussion forums students and instructors may post and respond to text-based messages, and there may be several responses and counter-responses to the same question forming a threaded discussion. The text-based messages that are posted within this medium to create interaction are described in terms of student and instructor asynchronous discourse. 
Student and instructor asynchronous discourse is helpful for encouraging in-depth and more thoughtful discussion(s). Asynchronous discourse enhances the possibility for creating student learning communities. Since online students and instructors represent themselves through text-based messages, interaction requires making one's text comprehensible, meaningful, and respectful.

Learning occurs when online students and instructors express and exchange opinions, expertise, and ideas using instructor-student discourse. This study builds upon and extends the facilitation research of others (e.g., Anderson et al., 2001; Collins, 1997; Swan, 2001; Chou, 2001; House, 1999; Deal, 2002, Worley et al., 2002; Dziuban et al., 2001; Cannon et al., 2001; Shea et al., 2003; Dabbagh, 2003; Barab, et al., 2001; Pennington et al., 2004; Sherry, 2000; Overbaugh, 2002; Taylor, 2002).

Important research questions remain regarding the extent of instructor discourse and the extent of student discourse. For example, what is the extent of instructor discourse needed to foster student satisfaction in the online learning environment? This study is grounded on the assumption that student satisfaction plays an important role in the vitality of the online learning institution. Building on this assumption, in conjunction with the existing research literature, this study recognizes the importance of interactive discourse as a means of fostering a sense of community through asynchronous discourse. This study empirically examined the extent to which the extent of instructor asynchronous discourse directly affects the extent of student asynchronous discourse. A better understanding of this relationship may provide meaningful insights toward pedagogical theory and corresponding instructional practices associated with students within the post-secondary online learning environment.

\section{REVIEW OF THE LITERATURE}

Asynchronous discourse (e.g., email and threaded discussions) provides opportunities for online students to communicate and collaborate with peers and the instructor and to build and refine their knowledge. Asynchronous discourse has been conceptualized as an important success factor minimizing feelings of isolation and fostering a sense of connection among students (e.g., Picciano, 2002; Richardson \& Swan, 2001).

Online institutions of higher education may create policies for the minimum number of mandatory postings by online students in order to receive academic finite credit. Overbaugh (2002) recommends that online instructors emphasize to students that credit will only be assigned for high-quality, thoughtful, and original postings. Kearsely (2002) and Mason (1991) recommend that online instructors provide easy access to asynchronous discourse and post questions for students to be challenging enough to validate responses yet not so challenging for students to experience failure.

Pedagogy in the online learning environment includes teaching methods related to the engagement, reinforcement, and motivation of online students. Pedagogy also includes feedback, evaluation, and curriculum. Discourse is critical to motivation and engagement of online students in active learning (Anderson et al., 2001) and supports both academic and social needs (Chou, 2001). Researchers suggest that student asynchronous discourse should provide opportunities for online students to reflect on and revise their academic work (Barab, Thomas, \& Merrill, 2001).

Online instructors may create a virtual community using both pedagogical strategies and Internet technologies. They assist students to thrive by using effective interactive asynchronous discourse where students share their feelings or experiences or ideas and examine course issues (Barab, et al., 2001; Pennington et al., 2004). They may create a fully interactive learning environment. They make certain that online students are participating in the asynchronous discourse in order to develop a cohesive online learning community. They develop meaningful and accurate course content as expert consultants. They encourage deeper analysis of the course content by asking thought-provoking questions in the student discourse in order to motivate and encourage online students to produce high quality academic work online (Devi, 2001 and Furst-Bowe, 1997). These multiple roles of the online instructor require time commitment and a great deal of written communication (Tomlinson, 2002). Kocktanek (2000) asserts that asynchronous courses require approximately two to four times as much facilitative interaction as a more traditionally delivered lectured course. 


\section{RESEARCH METHODOLOGY}

This study's path analysis model is grounded on the theoretical and empirical research literature reviewed (Anderson et al., 2001; Cannon et al., 2001; Chou, 2001; Dabbagh, 2003; Deal, 2002; Dziuban et al., 2001; House, 1999; Overbaugh, 2002; Pennington et al., 2004; Shea et al., 2003; Sherry, 2000; Swan, 2001; and Taylor, 2002). A specific quantitative path analysis model was developed in order to test and analyze the direct hypothesized relationship that is graphically illustrated in Figure 1. It was hypothesized that the extent of instructor asynchronous discourse would have a direct positive effect on the extent of student asynchronous discourse.

\section{RESEARCH DESIGN}

The researcher used quantitative path analysis, content analysis, and course evaluation surveys to conduct this study. Quantitative path analysis procedures were used to examine the direct hypothesized relationship. Content analysis procedures were used on the computer-mediated transcripts of threaded discussions between students and instructors within several courses offered entirely online by an accredited institution of higher education. Course evaluation surveys were used to measure student satisfaction with learning in the online learning environment.

\section{CONTENT ANALYSIS}

The primary data source for this study was the computer-mediated transcripts generated by online students and their course instructor as they participated in the asynchronous discourse component of their respective online course. With the inherent capacity to archive asynchronous discourse, computer-mediated transcripts provided an ideal means to identify and analyze the extent of asynchronous discourse exchanged among the participants in each of the online courses involved in this study. Content analysis procedures were used to analyze threaded discussions, posted by students and instructors and quantify: (a) the extent of student asynchronous discourse; and (b) the extent of instructor asynchronous discourse.

\section{COURSE EVALUATION SURVEYS}

The researcher collected data from an online educational institution offering graduate level courses in Education and Information Technology. The educational institution requires students to respond to course evaluation survey questions designed to assess student perceptions of the administrative, technological, and instructional components of the online educational institution. The survey questions are about rating the online course, the online instructor, and the online institution. The last survey question asks students to write about their online experience. The researcher received copies of the responses only to the last survey question (qualitative data).

\section{PARTICIPANTS AND SETTING}

The setting consisted of a small institution of higher education offering graduate level degree programs entirely online. The participating institution is: (a) accredited by the appropriate accrediting body; (b) there are no residency requirements; (c) all communications and interactions between students and instructors take place online using email and threaded discussions using the institution's computer server; and (d) students are required to participate in asynchronous discussion forums.

Each graduate course consists of eight modules. Each module consists of: (a) learning objectives; (b) background reading materials based on assigned textbook(s) or online databases of publications; (c) an assignment; (d) a mandatory asynchronous computer mediated discussion; and (e) online research required for the successful completion of a final project.

It is the institution's policy to use mandatory asynchronous discussions as an effort to generate an ongoing interactive dialogue between students and the instructor. It is also the institution's policy to require students to complete and submit a course evaluation survey electronically to the educational institution at the end of an academic session which covers a ten-week period. 
Online discussions are initiated at the start of each module with a question posted by the instructor. Online students are instructed and expected to respond to threaded questions by a certain due date.

\section{DATA COLLECTION}

The researcher was given access to the institution's online database containing copies of the threaded discussions and course evaluation surveys. The researcher selected randomly $85 \%$ of the database's threaded discussions. The researcher also selected randomly $85 \%$ of only the last question of the course evaluation survey asking students to write about their online experience. The retrieved data were saved into a text file which was edited. Edits included the replacement of names of both online students and instructors with pseudo names and the replacement of actual student ID numbers with pseudo numbers. The edited data were saved into one database file using Microsoft Access in order to perform content analysis.

\section{DATA ANALYSIS}

Transcribed qualitative data were annotated and entered into SPSS 11.5 for Windows for analysis. In this study's path analysis model (Figure 1), the extent of student asynchronous discourse and the extent of instructor asynchronous discourse were continuous variables.

Descriptive statistics were performed in order to compute the student $n$ size and the extent of student discourse (number of student postings), and the instructor $n$ size and the extent of instructor discourse (number of instructor postings). Descriptive statistics were also performed to compute the mean and standard deviation of the number of student postings and the number of instructor postings.

Path coefficients for the direct relationship between number of student postings and the number of instructor postings with $\alpha=.05$ and $p<.05$ for statistical significance were calculated. The extent of instructor discourse was the predictor variable and the extent of student discourse was the criterion variable.

\section{RESEARCH RESULTS}

Table 1 presents the descriptive data for student participation. The number of student postings represents the extent of asynchronous student discourse.

Table 1

Descriptive Data for Student Participation

\begin{tabular}{ccc}
\hline $\begin{array}{c}\text { Student } \\
\mathrm{n} \text { Size }\end{array}$ & $\begin{array}{c}\text { Number of } \\
\text { Student Postings }\end{array}$ & $\mathrm{M}(\mathrm{SD})$ \\
\hline 113 & 1,898 & $16.81(2.66)$
\end{tabular}

Table 2 presents the descriptive data for instructor participation. The number of instructor postings represents the extent of asynchronous instructor discourse.

Table 2

Descriptive Data for Instructor Participation

\begin{tabular}{ccc}
\hline $\begin{array}{c}\text { Instructor } \\
\mathrm{n} \text { Size }\end{array}$ & $\begin{array}{c}\text { Number of } \\
\text { Student Postings }\end{array}$ & M(SD) \\
\hline 5 & 2,015 & $17.84(2.74)$
\end{tabular}

The mean number of instructor postings was $17.84(n=5, S D=2.74)$ and the mean number of student postings was $16.81(n=113, S D=2.66)$. The relationship between the number of instructor postings and the number of student postings was of statistical significance $(r=.831, p<.01)$. The Pearson Correlation value for the 
relationship between the extent of student discourse and the extent of instructor discourse was found to be $.831(* *)$ where $*=p<.05 ; * *=p<.01$ level (2-tailed). Correlation coefficients of determination indicated that this relationship was of practical significance (the variance in the extent of student postings was associated with the extent of instructor postings). Thus, this direct relationship was both of statistical and practical significance.

\section{QUALITATIVE DATA ANALYSIS}

In order to provide further insights toward the implications of the quantitative findings and strengthen possible interpretations, the researcher analyzed the responses to the last course survey question asking students to write about their online experience. Some of the qualitative data are presented in the form of excerpts with regard to the hypothesized relationship between the number of instructor postings and the number of student postings (Figure $1)$.

- $\quad$ During the online discussions, I was encouraged to give more in-depth and thoughtful answers during the online discussions in this course.

- It was productive to share ideas and discuss the contents of the course with other learners. Online discussions reduced my feeling of being lost and confused.

- $\quad$ This was my first online graduate level course. Thank you for monitoring the quality of our interactions and for providing me with meaningful and timely feedback.

- I am really pleased I took this online course. There was a constant interaction with you and you answered all of my questions.

- $\quad$ I may have been lost without your timely interaction. Thank you for strengthening class community during the online discussions. My success in this course depended on you!

- It seems that it a natural expectation for the online instructor to be in constant communication with learners. The more you interacted with me the more I was encouraged to fully participate in the online discussions.

- $\quad$ The number of times you posted to the discussion board affected how often I posted responses. In this class, communication with you was timely and positive. Your motivation and enthusiasm and frequent postings made a big difference in this class.

- Your frequent interactions in this class helped me post to your thought-provoking questions with zeal.

- I consider your frequent participation in the online discussions a collegial contribution. I would recommend this course to others because your commitment helped me succeed.

\section{INTERPRETATIONS AND IMPLICATIONS FOR POLICY AND PRACTICE}

There are some implications that the findings of this study may have for policy and practice. The quantitative data suggest that there is a positive direct effect of the extent of instructor discourse on the extent of student discourse in the online learning environment. The quantitative data also suggest that students who reported high levels of instructor discourse during mandatory online discussions also reported higher levels of student discourse.

The qualitative data suggest that the role of the instructor is unique affecting interactions between students and the instructor. The qualitative data also suggest that the instructor is expected to interact with students as continuously and efficiently as possible and to monitor the quality and quantity of student's academic work. The qualitative data also suggest that the greater the extent of instructor discourse the greater the extent of learner discourse.

These findings suggest that students participate more in online discussions when the instructor interacts frequently and in a timely fashion with students. These findings suggest that instructors should initiate, monitor, guide and frequently participate in online discussions. These findings suggest that in the online learning environment teaching presence is created with frequent instructor discourse and social presence is created with frequent instructor and student discourse. These findings point to the importance of creating opportunities for students to interact with the instructor. 
Online course developers, instructors, and administrators should support both teaching presence and social presence by creating opportunities for instructors and students to build online communities. Online course developers, instructors, and administrators should work collaboratively to facilitate frequent interactions with the instructor and between the instructor and students.

The findings of this study suggest that course design and course delivery methods such as asynchronous student and instructor discourse stimulate electronic learning satisfaction. Also, the findings of this study suggest that the role and commitment of the online instructor in prompting student discourse for learning stimulation and motivation (i.e., guide, motivate, monitor, and encourage students to fully participate in online discussions) is important in order to meet students' needs and foster student satisfaction.

Policy makers, administrators, and faculty may wish to use the findings of this study to develop programmatic strategies and operational activities to improve course design. Course design should include a userfriendly interface that online students and the instructor could use in order for students to interact with other students and for the instructor to communicate with students. Course curriculum should include with the actual course content assessment and evaluation criteria for student participation in online discussions. Course delivery should include asynchronous text-based threaded discussions and email, and perhaps other synchronous methods of communication in order to foster student satisfaction by creating an interactive online learning environment among students and between the instructor and students.

Policy makers may wish to use the findings of this study when designing and implementing online course design, curriculum, and delivery in order to improve online enrollment and retention and perhaps to increase online enrollment (i.e., develop enrollment management strategies).

\section{LIMITATIONS OF THE STUDY}

In conjunction with this research study's assumptions, there are some limitations to this study that may limit its generalizability to other research settings. The findings of this study might not be generalizable to the entire spectrum of online learners. The results may be indicative of only the responding sample and boundaries of this population of online learners. The constructs of this study were analyzed at a given point in time while dynamic technological changes can occur in the online learning environment and in research findings. This research study did not develop an instrument for measuring student satisfaction or success with the asynchronous online learning systems.

\section{CONCLUSION}

Stakeholders of the online institution should take into consideration the aforementioned recommendations that may contribute to a better understanding of the factors that affect student success in the online learning environment. Specifically, the online institution should develop online courses that create a virtual community using course delivery methods such as asynchronous student and instructor discourse that stimulate electronic learning success.

Administrators of the online institution should work in consultation with policy makers and faculty in order to develop programmatic strategies and operational activities that may improve course design, curriculum, and delivery of the online courses. For example, programmatic strategies that consider the extent of instructor and student discourse may help the online institution with online enrollment and retention and may contribute to learner success.

\section{REFERENCES}

1. Anderson, T., Rourke, L., Garrison, D. R., \& Archer W. (September, 2001). Assessing teaching presence in a computer conferencing context. Journal of Asynchronous Learning Networks, 5 (2). Retrieved February 2004, from http://www.aln.org/publications/jaln/v5n2/v5n2_brown.asp.

2. Arbaugh, J. B. (2000). Virtual classroom characteristics and learner satisfaction with Internet-based MBA courses. Journal of Management Education, 24(1), p. 32. 
3. Bernard, R.M., \& Amundsen, C.L. (1989). Antecedents to dropout in distance education: Does one model fit all? Journal of Distance Education, 4(2), p. 25.

4. Brown, R. 2001. (2001). The process of community building in distance learning classes. Journal of Asynchronous Learning Networks, 5(2). Retrieved Jan 2007, from http://www.aln.org/publications/jaln/v5n2/v5n2_brown.asp.

5. Bullen, M. (1998). Participation and critical thinking in online university distance education. Journal of Distance Education, 13(2), 1-32.

6. Cannon, M. M, Umble, K.E., Steckler, A., \& Shay, S. (2001). We're living what we're learning: Learner perspectives in distance learning degree and certificate programs in public health. Journal of Public Health Management and Practice, 7(1), p. 49.

7. Chou, C. C. (2001). Formative evaluation of synchronous CMC systems for a learner-centered online course. Journal of Interactive Learning Research, 12(213), pp.173-192.

8. $\quad$ Daly, J.A., \& Kreiser, P.O. (1992). Affinity strategies. Advances in Experimental Psychology, 7, pp. 157215 .

9. Dede, C. (1996). The evolution of distance education: Emerging technologies and distributed learning. The American Journal of Distance Education, 10(2), pp. 4-36.

10. Furst-Bowe, J. (1997). Comparison of learner reactions in traditional and videoconferencing courses in training and development. International Journal of Instructional Media, 24(3), p. 197.

11. Gunawardena, C.N. and Zittle, F. ,J. (1997). Social presence as a predictor of satisfaction within a computer-mediated conferencing environment. The American Journal of Distance Education, 11(3), pp. 826.

12. Havice, P. \& Chang, C. (2002). Fostering community through the use of technology in a distributed learning environment. College Learner Affairs Journal, 22(1), p. 74.

13. House, Daniel (1999). The effect of entering characteristics and instructional experiences on learner satisfaction and degree completion. International Journal of Instructional Media, 26(4), p. 423.

14. Kearsley, G. (2002). Is online learning for everybody? Educational Technology, 42(1)

15. King, P., \& Hildreth, D. (2001). Internet Courses: Are they worth the effort? Journal of College Science Teaching, 31(2), pp. 112-115.

16. Overbaugh, Richard (2002). Undergraduate education major's discourse on an Electronic mailing list. Journal of Research on Technology in Education. Eugene, 35(1), p. 117.

17. Palloff, R.M., \& Pratt, K. (1999). Building learning communities in cyberspace: Effective strategies for the online classroom. Jossey-Bass Inc., Publishers.

18. Pennington, T., Wilkinson, C., \& Vance, J. (2004). Physical Educators Online: What is on the Minds of Teachers in the Trenches? Physical Educator, 61(1), P. 45.

19. Picciano, A.G. (2001). Distance Learning: Making Connections across Virtual Space and Time. Upper Saddle River, NJ: Prentice-Hall, 2001.

20. Rich, M. (1997). A learning community on the Internet: an exercise with masters learners. Proceedings of the Third Annual Conference of the AIS, Indianapolis, IN.

21. Richardson, J., \& Swan, K. (February, 2003). Examining social presence in online courses in relation to learners' perceived learning and satisfaction. Journal of Asynchronous Learning Networks. Retrieved Jan 2007 from http://www.aln.org/publications/jaln/v7n1/v7n1 richardson.asp

22. Schott Karr, S. (2002). Anytime / anyplace learning. Financial Executive, 18 (8), p. 38.

23. Swan, K. (2001). Virtual interaction: Design factors affecting learner satisfaction and perceived learning in asynchronous online courses. Distance Education, 22(2), p. 306.

24. Taylor, R. (2002). Pros and cons of online learning - a faculty perspective. Journal of European Industrial Training, Bradford, 26(1), p. 24.

25. Vygotsky, L. (1978). Mind in society: The development of higher psychology processes. Cambridge, MA: Harvard University.

26. Whitney Gibson, J. \& Tesone, D. \& Blackwell, C. (2001). The journey to cyberspace: Reflections from three online business professors. Advanced Management Journal, 66(1), p. 30.

27. Worley, David, \& Chesebro, James (2002). Goading the discipline towards unity: Teaching communication in an Internet environment - a policy research analysis. Communication Quarterly. University Park, 50(2), p. 171. 